\title{
DESENVOLVIMENTO DE UM SISTEMA DE FILTRAÇÃO E TITULAÇÃO PARA DETERMINAÇÃO DA ACIDEZ DE ÁCIDOS HÚMICOS
}

\author{
Alexandre G. S. Prado, Sidney M. Souza, Wilson T. Lopes da Silva e Maria O. de O. Rezende* \\ Instituto de Química de São Carlos - Universidade de São Paulo - CP 780 - 13560-970 - São Carlos - SP
}

Recebido em 17/8/98; aceito em 14/4/99

\begin{abstract}
DEVELOPMENT OF A FILTRATION AND TITRATION METHOD FOR THE DETERMINATION OF THE ACIDITY OF HUMIC ACIDS. The acidity determinations method of humic acids (HA) content was developed by Schnitzer and Gupta and is a very well known procedure. Nevertheless, care is necessary to prevent measure errors due to non-controlled $\mathrm{BaCO}_{3}$ production, during the filtration and titration of $\mathrm{HA}$ total acidity. To overcome this problem, we developed in our laboratory a simple filtration and titration system for the determination of $\mathrm{HA}$ acidity under inert atmosphere. This system enables a better reproducibility and accuracy of total, carboxylic and phenolic acidity measures than those by Schnitzer and Gupta method.
\end{abstract}

Keywords: humic acids; acidity; titration method.

\section{INTRODUÇÃO}

Ácidos húmicos $(\mathrm{AH})$ são substâncias que desempenham importante papel no ambiente ${ }^{1}$.

A germinação de sementes, por exemplo, está ligada diretamente à quantidade de ácidos húmicos no solo, pois, graças à coloração escura que possuem, absorvem bem o calor. A elevada retenção de água pelos ácidos húmicos auxilia na conservação dos solos contra a erosão ${ }^{1,2}$. Os ácidos húmicos cimentam as partículas do solo em agregados ao se combinarem com os minerais e também atuam como fertilizantes naturais, cedendo nutrientes às plantas como $\mathrm{NH}_{4}{ }^{+}, \mathrm{NO}_{3}{ }^{-}, \mathrm{SO}_{4}{ }^{2-}$, resultantes de sua decomposição ${ }^{1,2}$.

Um dos aspectos mais estudados sobre os ácidos húmicos é a sua capacidade de complexação com metais e agroquímicos $^{3-5}$. A excepcional capacidade de complexação com metais ocorre devido ao grande número de grupos funcionais contendo oxigênio encontrados em sua estrutura, na forma de grupos ácidos: carboxílicos e fenólicos ${ }^{1,3-7}$. A determinação correta da acidez do ácido húmico, portanto, é de suma importância, visto que sua acidez está diretamente relacionada com sua reatividade.

O método mais utilizado na determinação de acidez do ácido húmico foi desenvolvido por Schnitzer e Gupta ${ }^{8}$. Por este método, observam-se duas reações distintas. Uma para a determinação da acidez carboxílica e a outra para acidez total. Acidez fenólica é obtida pela diferença entre acidez total e a carboxílica.

\section{Acidez carboxílica ${ }^{8}$}

A determinação da acidez carboxílica é feita pela reação do ácido húmico com acetato de cálcio. $\mathrm{O}$ acetato de cálcio reage apenas com os grupos carboxílicos do ácido húmico, desprotonando-os(Figura 1).

A reação do ácido húmico com o acetato de cálcio segue a seguinte estequiometria:

\section{$2 \mathrm{R}-\mathrm{COOH}+\left(\mathrm{CH}_{3} \mathrm{COO}\right)_{2} \mathrm{Ca}=(\mathrm{R}-\mathrm{COO})_{2} \mathrm{Ca}+2 \mathrm{CH}_{3} \mathrm{COOH}$}

Na determinação da acidez carboxílica o ácido húmico é

\footnotetext{
*e-mail:mrezende@iqsc.sc.usp.br
}

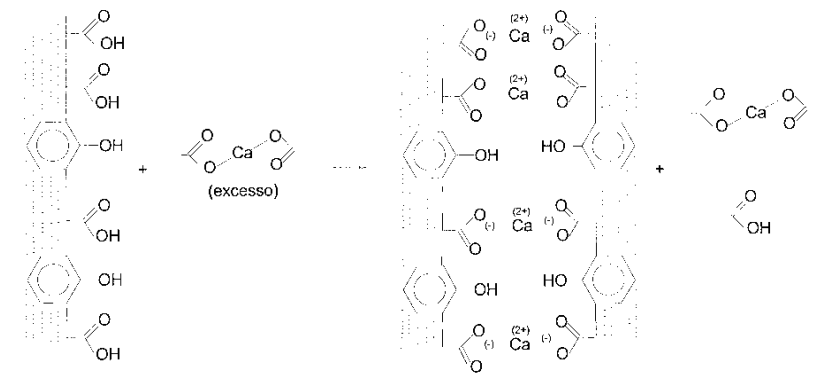

Figura 1. Esquema hipotético do ácido húmico com ênfase à visualização dos grupos carboxílicos e fenólicos e a sua reação com acetato de cálcio.

colocado em presença com uma quantidade de acetato de cálcio em solução aquosa desionizada. A solução permanece sob agitação durante um dia, isolada do ar. A suspensão formada é filtrada e lavada com água pura desionizada. A mistura (filtrado + água de lavagem) é titulada com solução padrão de $\mathrm{NaOH}$ até $\mathrm{pH}=9,8$. A acidez é determinada segundo a equação 1 .

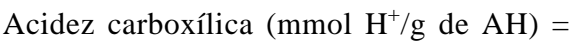

$\left(\mathrm{V}_{\mathrm{B} 2}-\mathrm{V}_{\mathrm{B} 1}\right) \times \mathrm{C}_{\mathrm{B}} \times 1000 / \mathrm{m}_{\mathrm{AH}}$

$\mathrm{Na}$ qual $\mathrm{V}_{\mathrm{B} 1}$ e $\mathrm{V}_{\mathrm{B} 2}$ representam o volume $(\mathrm{mL})$ de base padrão usado para a titulação do branco e da amostra, respectivamente, $C_{B}$ é a concentração da base $(\mathrm{mol} / \mathrm{L})$ e $\mathrm{m}_{\mathrm{AH}}$ é a massa de ácido húmico, em miligramas.

\section{Acidez total ${ }^{8}$}

A determinação da acidez total é feita pela reação do ácido húmico com o hidróxido de bário, que reage tanto com os grupos carboxílicos como com os fenólicos (Figura 2).

A reação do ácido húmico $(\mathrm{AH})$ com $\mathrm{Ba}(\mathrm{OH})_{2}$ segue a seguinte estequiometria:

$$
2 \mathrm{AH}+\mathrm{Ba}(\mathrm{OH})_{2}=\mathrm{BaA}_{2}+2 \mathrm{H}_{2} \mathrm{O}
$$

$\mathrm{Na}$ determinação da acidez total segue-se o mesmo processo da acidez carboxílica, porém coloca-se o ácido húmico para reagir com excesso de hidróxido de bário, titulando-se o filtrado e 


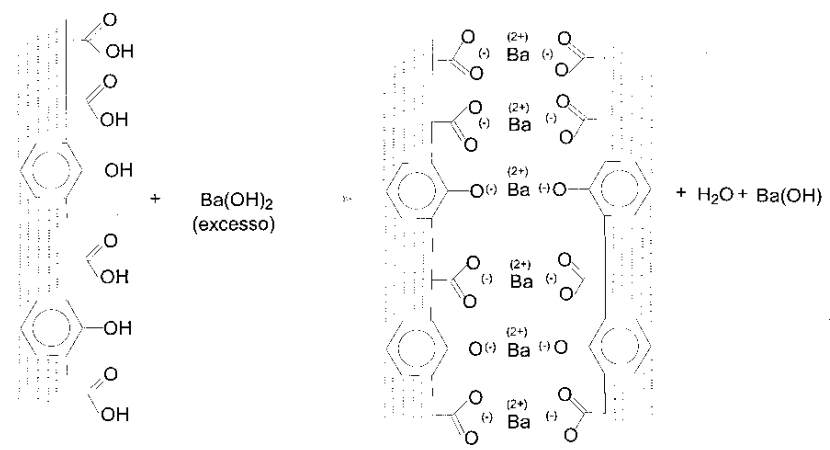

Figura 2. Esquema hipotético do ácido húmico com ênfase aos grupos carboxílicos e fenólicos e sua reação com hidróxido de bário.

a água de lavagem com $\mathrm{HCl}$ até $\mathrm{pH}=8,4$. A acidez é determinada pela equação 2 .

acidez total $\left(\mathrm{mmol} \mathrm{H} \mathrm{H}^{+} / \mathrm{g}\right.$ de $\left.\mathrm{AH}\right)=$

$\left(\mathrm{V}_{\mathrm{A} 1}-\mathrm{V}_{\mathrm{A} 2}\right) \times \mathrm{C}_{\mathrm{A}} \times 1000 / \mathrm{m}_{\mathrm{AH}}$

$\mathrm{Na}$ qual $\mathrm{V}_{\mathrm{A} 1}$ e $\mathrm{V}_{\mathrm{A} 2}$ representam os volumes, em mililitros, da solução ácida padronizada usada para a titulação do branco e da amostra, respectivamente. $\mathrm{C}_{\mathrm{A}}$ é a concentração do ácido em mol/L e $\mathrm{m}_{\mathrm{AH}}$ é a massa de $\mathrm{AH}$ (em mg) usada na titulação.

A acidez fenólica foi determinada por diferença entre a acidez total e a acidez carboxílica.

A determinação da acidez carboxílica pelo método de Schnitzer e Gupta ${ }^{8}$ é reprodutível e não exige maiores cuidados, porém a determinação da acidez total não é muito reprodutível.

Durante a filtração e titulação a solução saturada de humato de bário, em presença de hidróxido de bário, fica em exposição ao ar, formando $\mathrm{BaCO}_{3}$. Um dos erros encontrados nas medidas da acidez total do ácido húmico deve-se, portanto, à formação de carbonato de bário, pela presença de $\mathrm{CO}_{2}$ do ar durante a filtração e titulação.

A formação de $\mathrm{BaCO}_{3}$ leva a um erro durante a titulação, devido à diminuição da concentração de $\mathrm{OH}^{-}$na solução, segundo as equações:

\begin{tabular}{lllll}
$\mathrm{CO}_{2}+\mathrm{H}_{2} \mathrm{O}$ & $\rightarrow$ & $\mathrm{H}_{2} \mathrm{CO}_{3}$ \\
$\mathrm{Ba}(\mathrm{OH})_{2}+$ & $\mathrm{H}_{2} \mathrm{CO}_{3}$ & $\rightarrow$ & $\mathrm{BaCO}_{3}+2 \mathrm{H}_{2} \mathrm{O}$ \\
\hline $\mathrm{CO}_{2}+\mathrm{Ba}(\mathrm{OH})_{2}$ & $\rightarrow$ & $\mathrm{BaCO}_{3}+\mathrm{H}_{2} \mathrm{O}$
\end{tabular}

A formação de carbonato leva a um resultado de acidez equivocado do ácido húmico, pois quando o $\mathrm{H}_{2} \mathrm{CO}_{3}$ reage com $\mathrm{Ba}(\mathrm{OH})_{2}$, retira $\mathrm{OH}^{-}$da solução de uma forma aleatória. Assim, podem ser determinados valores de acidez muito dispersos já que a quantidade de $\mathrm{CO}_{2}$ em um laboratório é variável, acarretando grandes desvios nos valores obtidos e pondo em dúvida o resultado final.

Para resolver este problema, foi desenvolvido em nosso laboratório um sistema de filtração e titulação para determinação da acidez total do ácido húmico que apresenta uma ótima reprodutibilidade e exatidão dos resultados.

\section{PARTE EXPERIMENTAL}

\section{Materiais}

Na determinação da acidez dos ácidos húmicos foram usados os seguintes materiais e reagentes: mesa agitadora TECNAL TE - 141, pHmetro Mettler Toledo, $\mathrm{Ba}(\mathrm{OH})_{2}$ P.A. Vetec, $\mathrm{H}_{3} \mathrm{CCOONa}$ P.A. Merck, NaOH P.A. Synth, HCl P.A.
Merck, $\mathrm{N}_{2}$ (g) White Martins, $\mathrm{C}_{7} \mathrm{H}_{6} \mathrm{O}_{2}$ P.A. Merck e ácido húmico de uma turfa das margens do Rio Mogi-Guaçu, no município de Luiz Antônio purificado em nosso laboratório.

\section{PROCEDIMENTO}

\section{Acidez carboxílica ${ }^{8}$}

A amostra de ácido húmico, $50 \mathrm{mg}$, foi colocada em um erlenmeyer juntamente com $50 \mathrm{~mL}$ de solução de $0,2 \mathrm{~mol} / \mathrm{L}$ de acetato de cálcio em água, livre de $\mathrm{CO}_{2}$. A solução ficou em agitação por 24 horas. A suspensão foi filtrada em papel de filtro Whatman \# 42. O resíduo lavado com água milli-Q* livre de $\mathrm{CO}_{2}$. A mistura (filtrado + água de lavagem) foi titulada com solução de $\mathrm{NaOH} 0,100 \mathrm{~mol} / \mathrm{L}$. A variação do $\mathrm{pH}$ foi acompanhada com auxílio de um pHmetro, até $\mathrm{pH}=9,8$.

\section{Acidez total e fenólica ${ }^{8}$}

Foi colocado em $20 \mathrm{~mL}$ de solução de hidróxido de bário $0,125 \mathrm{~mol} / \mathrm{L}, 50 \mathrm{mg}$ de ácido húmico. A solução ficou sob agitação durante 24 horas, isolada do ar. Da mesma maneira foi feito o preparo do branco, constituído apenas por $20 \mathrm{~mL}$ de solução de $\mathrm{Ba}(\mathrm{OH})_{2} 0,125 \mathrm{~mol} / \mathrm{L}$. A suspensão foi filtrada com o auxílio papel de filtro whatman \# 42. O resíduo foi lavado com água ultra-pura, livre de $\mathrm{CO}_{2}$. A mistura (filtrado + água de lavagem) foi titulada com solução padronizada de $\mathrm{HCl} 0,05$ $\mathrm{mol} / \mathrm{L}$ padronizada, sob atmosfera inerte. A titulação foi acompanhada com auxílio de um pHmetro até pH 8,4.

$\mathrm{O}$ desvio encontrado nos resultados da acidez total levaram ao desenvolvimento de um novo sistema de filtração e titulação.

\section{Sistema de filtração e titulação da acidez}

A determinação da acidez total e carboxílica seguiu o mesmo procedimento de Schnitzer e Gupta ${ }^{8}$. Porém, durante a filtração da suspensão e titulação foi usado o esquema representado na Figura 3.

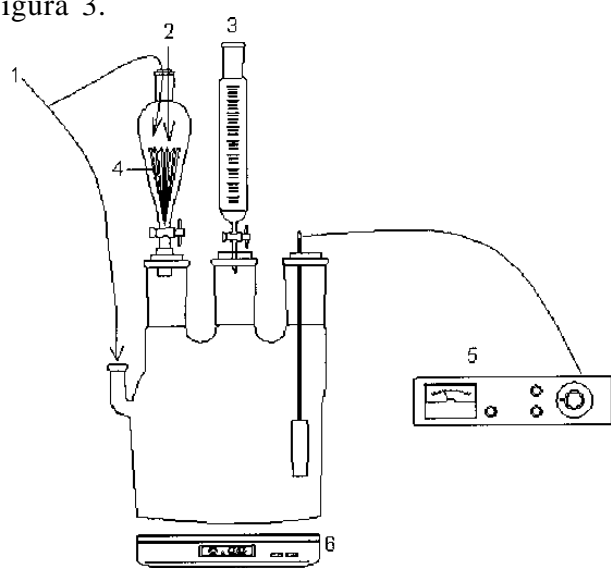

Figura 3. Esquema de filtração e titulação de ácido húmico para a determinação de acidez. (1) Entrada de $N_{2}$. (2) Funil isolado do ar. (3) Bureta com o titulante. (4) Filtro com a amostra. (5) pHmetro. (6) Agitador magnético.

Nesse sistema a solução é filtrada em um funil de separação que contém em seu interior um filtro de papel whatman \# 42 mantido isolado do ambiente, sob atmosfera de $\mathrm{N}_{2}$. O filtrado passa diretamente para uma cela, sob atmosfera de $\mathrm{N}_{2}$, onde estão acoplados o pHmetro e a bureta com o titulante, evitando, assim, o contato da amostra com o ar. O resíduo no funil é lavado com água ultra-pura desionizada. A solução é titulada sob agitação constante.

$\mathrm{O}$ sistema evita a formação de $\mathrm{BaCO}_{3}$, pois não permite o contato da amostra com o ar, durante a filtração e titulação. 


\section{RESULTADOS}

Nas Tabelas 1 e 2 são apresentados os valores de acidez para uma mesma amostra de ácido húmico, titulada segundo o procedimento padrão (Tabela 1), comparativamente ao procedimento utilizando o sistema em estudo (Tabela 2).

Tabela 1. Resultados de acidez do ácido húmico e do ácido benzóico $(\mathrm{mmol} \mathrm{H} / \mathrm{g})$ sem o uso do sistema de filtração e titulação.

\begin{tabular}{lcccc}
\hline Amostra & \multicolumn{3}{c}{$\begin{array}{c}\text { Ácido Húmico } \\
\text { Acidez }\end{array}$} & $\begin{array}{c}\text { Ácido } \\
\text { Benzóico }\end{array}$ \\
& carboxílica & fenólica & total & Acidez total \\
\hline 1 a replicata & 2,27 & 2,43 & 4,70 & 8,52 \\
2 a replicata & 2,34 & 3,00 & 5,34 & 8,39 \\
3 a replicata & 2,37 & 2,79 & 5,16 & 8,75 \\
Média & 2,33 & 2,74 & 5,07 & 8,55 \\
desvio padrão & 0,06 & 0,39 & 0,33 & 0,18 \\
\hline
\end{tabular}

Tabela 2. Resultados de acidez do ácido húmico, ácido

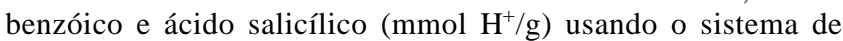
filtração e titulação.

\begin{tabular}{lccccc}
\hline Amostra & \multicolumn{2}{c}{$\begin{array}{c}\text { Ácido Húmico } \\
\text { Acidez } \\
\text { carboxílica }\end{array}$} & $\begin{array}{c}\text { Ácido } \\
\text { fenólica }\end{array}$ & $\begin{array}{c}\text { Ácido } \\
\text { Benzóico } \\
\text { Acidez }\end{array}$ & $\begin{array}{c}\text { Salicílico } \\
\text { total }\end{array}$ \\
\hline 1 $^{\text {a }}$ replicata & 2,27 & 1,78 & 4,05 & 8,36 & 9,15 \\
$2^{\text {a }}$ replicata & 2,30 & 1,77 & 4,07 & 8,43 & 9,25 \\
$3^{\text {a }}$ replicata & 2,30 & 1,82 & 4,12 & 8,38 & 9,20 \\
Média & 2,29 & 1,79 & 4,08 & 8,39 & 9,20 \\
desvio padrão & 0,02 & 0,05 & 0,03 & 0,04 & 0,05 \\
\hline
\end{tabular}

Para fins de aferição do método, fez-se também a titulação com e sem o sistema, de um ácido padrão para a determinação de sua acidez total. Foi escolhido para tal o ácido benzóico o qual possui uma acidez total de $8,2 \mathrm{mmol} \mathrm{H}^{+} / \mathrm{g}$. Sem o sistema de filtração, o valor obtido foi de $8,55 \pm 0,18 \mathrm{mmol} \mathrm{H}^{+} / \mathrm{g}$ (Tabela 1). Com o sistema, o valor foi de 8,39 $\pm 0,04 \mathrm{mmol} \mathrm{H}^{+} / \mathrm{g}$ (Tabela 2). Estes valores mostram que este sistema possibilita, além da melhor repetibilidade, uma maior exatidão das determinações de acidez.

Outrossim, fez-se a determinação da acidez total do ácido salicílico. Se se considerasse a substituição total dos dois hidrogênios ionizáveis da molécula, a acidez seria 14,48 mmol $\mathrm{H}^{+} / \mathrm{g}$. Entretanto, devido à formação da chamada "ponte salicílica", a ionização do segundo $\mathrm{H}^{+}$é desfavorecida, levando a valores mais baixos de acidez. Calculando-se a quantidade de $\mathrm{H}^{+}$através da segunda constante ácida, esse valor seria $8,6 \mathrm{mmol} \mathrm{H}^{+} / \mathrm{g}$. Fazendo-se a titulação do ácido salicílico com o sistema aqui desenvolvido, o valor encontrado foi de 9,20 $\pm 0,05 \mathrm{mmol} \mathrm{H}^{+} / \mathrm{g}$.

\section{CONSIDERAÇÕES FINAIS}

O sistema desenvolvido no laboratório, para filtração e titulação durante a determinação de acidez carboxílica e total, mostrou-se mais preciso e reprodutível que a metodologia padrão, sem o uso do sistema.

$\mathrm{Na}$ acidez carboxílica o erro e o desvio são pequenos, porém os resultados de acidez com aplicação do sistema são mais reprodutíveis. Já na acidez total e fenólica o erro é bem considerável, o que pode levar a resultados distorcidos. O sistema melhorou consideravelmente os resultados diminuindo o erro e o desvio-padrão das medidas, oferecendo ao método de determinação de acidez de ácidos húmicos maior confiabilidade e reprodutibilidade.

\section{AGRADECIMENTOS}

À Capes, pela concessão de bolsa a Alexandre Gustavo Soares Prado e a Wilson T. Lopes da Silva. À Fapesp, pela concessão de bolsa a Sidney Marques Souza, processo \# 97/020977. Ao $\mathrm{CNPq}$ pelo apoio financeiro.

\section{REFERÊNCIAS}

1. Barros, M. C. P.; Paula, J. R.; Rezende, M. O. O.; Quím. Nova 1994, 17, 376.

2. Schnitzer, M.; Skinner, S. I.; Soil Science 1968, 105, 392.

3. Burba, P.; Fresenius J. Anal. Chem. 1994, 348, 301.

4. Burba, P.; Rocha, J. C.; Klockow, D.; Fresenius J. Anal. Chem. 1994, 349, 800.

5. Burba, P.; Rocha, J. C.; Schulte, A.; Fresenius J. Anal. Chem. 1993, 346, 414.

6. Senesi, N.; Sposito, G.; Martin, J. D.; The Sci. Total. Environ. 1986, 55, 351

7. Ricca, G.; Frederico, L.; Astori, C.; Gallo, R.; Geoderma 1993, 57, 263.

8. Schnitzer, M.; Gupta, U. C.; Soil Science Proceedings 1965, 274, 274. 